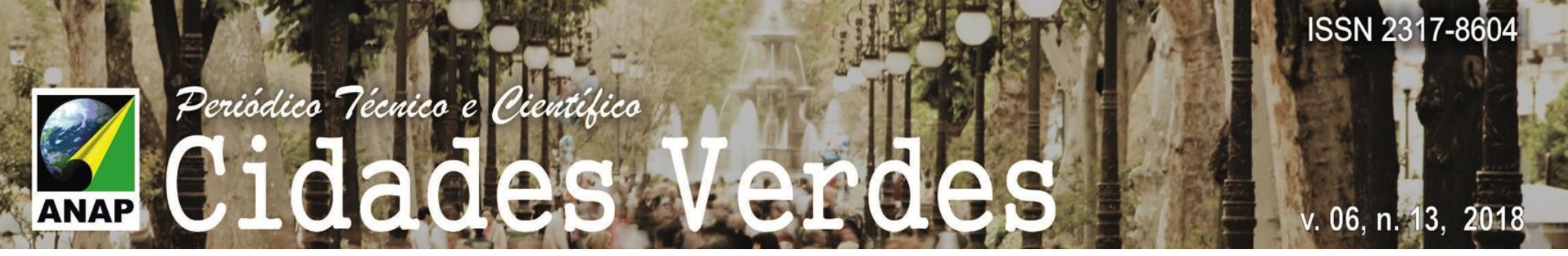

\title{
Acessibilidade na Residência Universitária da Universidade Federal Rural do Semi-Árido
}

Accessibility at the University Residence of the Rural Semi-Arid Federal University

Accesibilidad en la Residencia Universitaria en la Universidad Federal Rural del SemiArido

Lília Caroline de Morais Discente do curso de Arquitetura e Urbanismo, UFERSA, Brasil liliacaroline.m@gmail.com

\section{Cecília de Amorim Pereira} Discente do curso de Arquitetura e Urbanismo, UFERSA, Brasil ce.amorim09@gmail.com

\section{Eduardo Raimundo Dias Nunes} Professor Doutor do curso de Arquitetura e Urbanismo, UFERSA, Brasil. eduardo.dias@ufersa.edu.br 


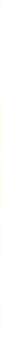

RESUMO

Acessibilidade consiste na eliminação de barreiras, físicas ou não, para possibilitar a inclusão de pessoas com necessidades especiais em diversas atividades do cotidiano, e, ao mesmo tempo, garantir uma melhor qualidade de vida. Entre essas atividades, a educação é um direito de todos, e, por esse motivo, as instituições, em seus respectivos níveis, devem proporcionar ambientes inclusivos aos indivíduos que compõem o corpo escolar. Este artigo tem como objetivo verificar a adaptação de uma residência universitária aos critérios de acessibilidade, considerando apenas as barreiras físicas. Para elaborar este diagnóstico, foram realizadas medições nas dependências do edifício, analisando a coerência destas informações com o projeto arquitetônico que a universidade forneceu e os parâmetros estabelecidos pela NBR 9050 da Associação Brasileira de Normas Técnicas (ABNT). A análise mostrou que o maior obstáculo para a acessibilidade do edifício se deu durante o processo de execução da obra, pois houve uma dispersão do que foi indicado no projeto, que por sua vez, atendeu aos critérios necessários. Devido ao esperado aumento na procura pelo programa de permanência que inclui a moradia, a universidade deverá se atentar para corrigir esse problema, pois somente assim, o edifício estará adequado para receber todos os estudantes e moradores.

PALAVRAS-CHAVE: Acessibilidade. Inclusão. Educação.

\section{ABSTRACT}

Accessibility consists of the elimination of barriers, physical or otherwise, to enable the inclusion of people with special needs in various activities of daily life, and, at the same time, ensure a better quality of life. Among these activities, education is a right for all, and for this reason, institutions at their respective levels should provide inclusive environments for the individuals who make up the school body. This article aims to verify the adaptation of a university residence to the criteria of accessibility, considering only the physical barriers. In order to elaborate this diagnosis, measurements were made in the building's premises, analyzing the coherence of this information with the architectural project and the parameters established by NBR 9050 of the Associação Brasileira de Normas Técnicas (ABNT). The analysis showed that the greatest obstacle to the accessibility of the building occurred during the process of xecution of the work, because there was a dispersion of what was indicated in the project, which in turn, met the necessary criteria. Due to the expected increase in demand for the permanence program, the university should take care to correct this problem, because only then, the building will be suitable to receive all students.

KEYWORDS: Accessibility. Inclusion. Education.

\section{RESUMEN}

La accesibilidad consiste en la eliminación de barreras físicas o no, para posibilitar la inclusión de personas con necesidades especiales en diversas actividades del cotidiano, y al mismo tiempo garantizar una mejor calidad de vida. Entre esas actividades, la educación es un derecho de todos, y, por ese motivo, las instituciones, en sus respectivos niveles, deben proporcionar ambientes inclusivos a los individuos que componen el cuerpo escolar. Este artículo tiene como objetivo verificar la adaptación de una residencia universitaria a los criterios de accesibilidad, considerando sólo las barreras físicas. Para elaborar este diagnóstico, se realizaron mediciones en las dependencias del edificio, analizando la coherencia de estas informaciones con el proyecto arquitectónico que la universidad suministró y los parámetros establecidos por la NBR 9050 de la Asociación Brasileña de Normas Técnicas (ABNT). El análisis mostró que el mayor obstáculo para la accesibilidad del edificio se dio durante el proceso de ejecución de la obra, pues hubo una dispersión de lo que fue indicado en el proyecto, que a su vez, atendió a los criterios necesarios. Debido al esperado aumento en la demanda por el programa de permanencia que incluye la vivienda, la universidad deberá atenderse para corregir este problema, pues sólo así, el edificio será adecuado para recibir a todos los estudiantes y habitantes.

PALABRAS CLAVE: Accesibilidad. Inclusión. Educación. 


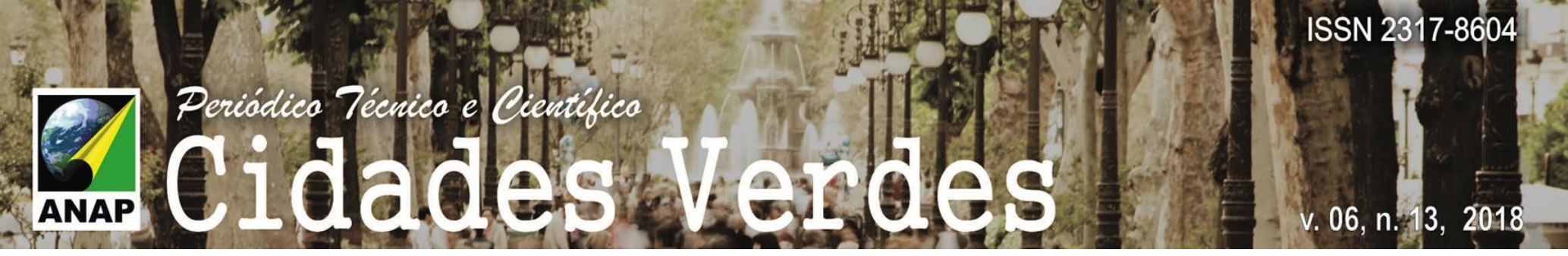

\section{INTRODUÇÃO}

Diante dos princípios da Educação Nacional Brasileira, que visam o ensino com igualdade de condição para o acesso e permanência na escola, o Estado deve se responsabilizar pelo desenvolvimento dos cidadãos, seu preparo para a cidadania e sua qualificação para o trabalho garantindo uma educação de qualidade, conforme o disposto no artigo 3 da Lei 9.394, de 20 de dezembro de 1996, que estabelece diretrizes e bases da educação nacional e o artigo 206 da Constituição Federal. Sendo a universidade uma instituição de ensino, seu papel se manifesta de diferentes maneiras, afim de solucionar os problemas e necessidades de uma sociedade para que, assim, ela possa se desenvolver. Dessa forma, percebe-se que a moradia estudantil é um componente social de fundamental importância na assistência universitária, pois são habitações que geralmente suprem as relações familiares e possuem como objetivo muito mais que abrigar os estudantes, mas permitir que seus moradores criem novos valores através da formação acadêmica, desenvolvendo processos alternativos de aprendizado que vão além das salas e laboratórios das universidades.

A presença dos alunos com deficiência tem oportunizado um profundo processo de reflexão sobre a acessibilidade em todos os seus sentidos nos mais diversos espaços. "Acessibilidade é, antes de mais nada, uma forma de inclusão social dando oportunidade a qualquer indivíduo de exercer a sua escolha individual e é, portanto, uma abordagem centrada na 'pessoa' e nas suas condições e capacidades físicas, sociais e econômicas" (ALMEIDA, 2012). É importante, então, reduzir o grau de dificuldade que essas pessoas enfrentam para realização de uma atividade devido às características físicas dos ambientes. Para tanto, é imprescindível o cumprimento das legislações e normas de acessibilidade para a melhoria das condições de acesso e uso do espaço universitário.

A Universidade Federal Rural do Semi-Árido é uma instituição de ensino superior localizada no interior do Rio Grande do Norte, dividida em quatro Centros Multidisciplinares. O objeto de estudo deste artigo é a Residência Universitária do Centro Multidisciplinar de Pau dos Ferros, município formado por 30 mil habitantes, distante cerca de 392,1 km da capital do Estado, Natal.

Segundo o Manual da Acessibilidade Espacial para Escolas (2009), do Ministério da Educação, barreiras físicas podem ser elementos naturais ou construídos, que dificultam ou impedem a realização de atividades desejadas de forma independente. É necessário que sejam feitas avaliações acerca das necessidades requeridas, pelas diversas deficiências, antes da elaboração de projetos de construção ou reforma de instituições de ensino, visando eliminar as barreiras que possam impedir a inclusão de todos os usuários aos espaços de educação.

“Um lugar acessível deve permitir, através da maneira como está construído e das características do seu mobiliário que todos possam participar das atividades existentes e que utilizem os espaços e equipamentos com igualdade e independência na medida de suas possibilidades." (Manual das Escolas Deficientes, 2009, p. 23). 


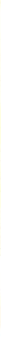

A NBR 9050 (ABNT, 2015), que trata da acessibilidade a edificações, mobiliário, espaços e equipamentos urbanos, determina as dimensões referenciais como as medidas entre $5 \%$ a $95 \%$ da população brasileira, que corresponde aos extremos formados por mulheres de baixa estatura e homens de estatura elevada. Esta norma estabelece, ainda, parâmetros de dimensões para cada tipo de atividade a ser exercida por pessoas sem nenhum tipo de deficiência e as pessoas que as apresentam. Como exemplo desses parâmetros, têm-se as rotas de circulação que, para serem consideradas acessíveis, devem apresentar, no mínimo, 0,90 metros de largura, com áreas de manobra de 1,20m a 1,50m de largura e diâmetro, a depender da manobra necessária, para possibilitar o deslocamento de pessoas em cadeiras de rodas.

Mobiliários com altura entre $0,60 \mathrm{~m}$ até $2,10 \mathrm{~m}$ do piso podem representar riscos para pessoas com deficiências visuais, caso tenham saliências com mais de $0,10 \mathrm{~m}$ de profundidade, conforme a NBR 9050 (ABNT, 2015, p. 10). Portanto, deve-se evitar colocar esses tipos de mobiliários em rotas acessíveis.

As áreas de transferência devem ter as dimensões mínimas de 0,80m por 1,20m, correspondentes ao módulo de referência da cadeira de rodas. Além disso, a altura do assento para o qual for feita a transferência deve ser semelhante à do assento da cadeira de rodas, segundo a NBR 9050 (ABNT, 2015, p.15), bem como, deve-se garantir condições de deslocamento, manobra e um ângulo de alcance que permita a execução adequada das forças de tração e compressão. Em toda área de transferência é imprescindível a existência de barras de apoio.

O item 4.6 da NBR 9050 (ABNT, 2015) apresenta as dimensões mínimas, máximas e confortáveis para o alcance manual frontal e lateral das pessoas em pé e sentadas, demonstrados nas imagens a seguir:

Figura 1: Alcance manual frontal - Pessoa em pé

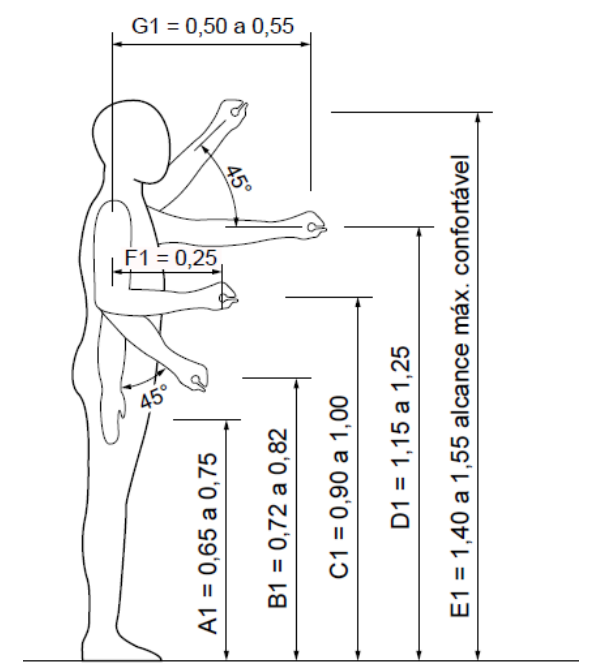

Fonte: ABNT NBR 9050, 2015 


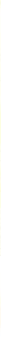

Figura 4: Alcance manual lateral sem deslocamento do tronco

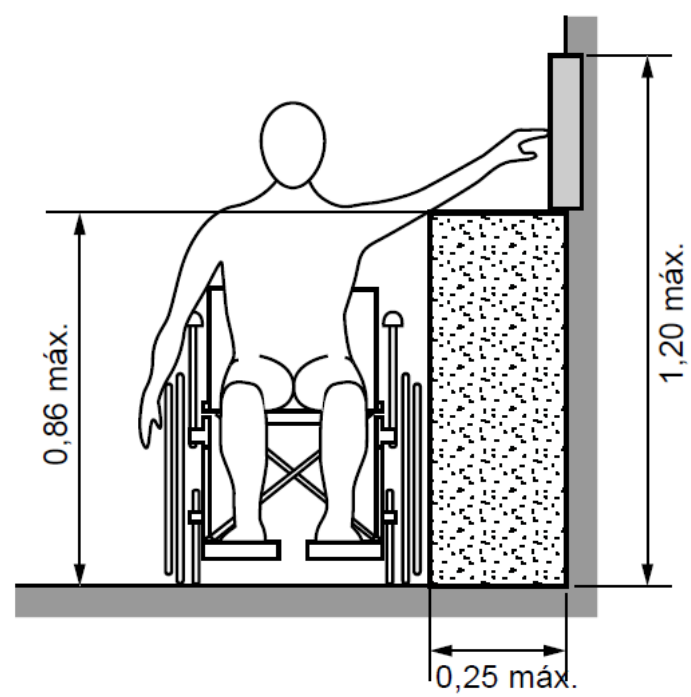

Fonte: ABNT NBR 9050, 2015

Diante desses parâmetros de alcance, a NBR 9050 (ABNT, 2015) apresenta as indicações para instalação de maçanetas e puxadores verticais e horizontes que devem estar em uma altura variável de $0,80 \mathrm{~m}$ a $1,10 \mathrm{~m}$ do piso acabado.

Tendo em vista que "a educação de qualidade é definida como aquela que é acessível e inclusiva, ou seja, que abre oportunidades para grupos historicamente excluídos e promove as reformas educacionais necessárias para que as escolas possam propiciar um ambiente adequado à aprendizagem no sentido de fortalecer as alianças e de enfatizar que nenhuma aprendizagem se dá no isolamento" (ALMEIDA, 2012). Diante disso, apesar de ser um estudo abrangente, este artigo apresenta uma análise acerca, especialmente, das questões de acessibilidade na estrutura física do edifício tomado como objeto de estudo, no que diz respeito a existência ou inexistência das condições mínimas de acessibilidade e, caso seja detectado a ausência de espaços acessíveis, propor sua adequação seguindo os parâmetros existentes na NBR 9050.

\section{OBJETIVOS}

Este estudo justifica-se pelo processo de expansão em que a universidade se encontra. Com isso, a demanda na busca pela moradia universitária tende a aumentar, bem como, a diversidade entre os alunos que pretendem pleitear uma vaga nessa residência. Então, este artigo possui como objetivo, além de possibilitar o conhecimento sobre o a importância e a necessidade da acessibilidade dos demais discentes, verificar se as dependências da residência universitária estão de acordo com os parâmetros definidos pela a NBR 9050 que trata da acessibilidade e pelo Manual da Acessibilidade Espacial para Escolas, do Ministério da 


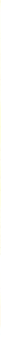

Educação, analisando as condições atuais de inclusão nas questões das adaptações arquitetônicas. Ao final desta pesquisa será possível definir se a universidade está preparada para receber alunos com necessidades especiais e, se não, como deverá proceder para se adequar às normas de inclusão dessas pessoas.

\section{METODOLOGIA}

O primeiro passo para elaboração deste estudo, foi a realização de uma leitura da norma brasileira NBR 9050 - Acessibilidade a Edificações, Mobiliário, Espaços e Equipamentos Urbanos - e do Manual de Acessibilidade Espacial Para Escolas para avaliar a residência da Universidade Federal Rural do Semi-Árido.

Esta residência universitária é composta por dois edifícios com projetos arquitetônicos semelhantes. Um desses edifícios é o bloco feminino e o outro é o bloco masculino, ambos comportam 80 estudantes. O segundo passo foi um levantamento simples de toda a edificação, dividido em duas visitas. Os parâmetros escolhidos para serem trabalhados foram as larguras das áreas de circulação e de manobra, dimensões referenciais para alcance manual, desníveis, presença de rampas e escadas, entre outros.

O primeiro levantamento foi feito dia 25 de janeiro de 2018 durante o turno vespertino e, usando uma trena eletrônica para captação das informações, onde foi conferido se as medidas do edifício, como altura das maçanetas, áreas de circulação, áreas de permanência, altura de pias e bancadas, largura das portas e medidas das rampas, estavam iguais as medidas indicadas no projeto. Nesta ocasião, foi levantada grande parte do edifício, exceto os quartos e a área de serviço, sala de informática e sala de estudos, que ficaram para uma próxima visita.

A mesma foi realizada somente dia 12 de março de 2018, dessa vez, com uso de uma trena comum. Após a coleta das medidas espaciais e do mobiliário presente em toda a edificação e alguns registros fotográficos, foi realizada uma comparação com as medidas indicadas nas plantas baixas afim de se conferir a fidedignidade da execução da obra com os parâmetros estabelecidos tanto na NBR quanto na cartilha do MEC.

\section{RESULTADOS}

Por se tratar de residência estudantil, o ambiente analisado segue os mesmos critérios de uma residência familiar. $\mathrm{O}$ acesso aos prédios da residência, se dá por uma via que interliga as áreas administrativas, salas de aulas, biblioteca e demais espaços da universidade que apresenta 1,60m de largura. Segundo a norma, a largura mínima de faixa livre ou passeio, destinada apenas à circulação de pedestres, é de $1,20 \mathrm{~m}$, sendo o dimensionamento realizado conforme a quantidade de pessoas circulam por ela. Ou seja, o que podemos perceber é que a rota de acesso está dentro das características exigidas. 

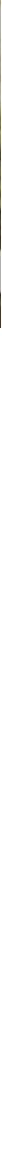

Fonte: CAPTURADA PELOS AUTORES.

No que diz respeito aos elementos de abertura de portas, a norma fala que não devem exigir firmeza do pulso para serem acionadas e possuir formato de fácil pega, além de serem instaladas a uma altura de até $1,10 \mathrm{~m}$ do piso acabado. Neste caso, há uma discrepância segundo o valor obtido no levantamento, pois as maçanetas se encontram a uma altura de $1,17 \mathrm{~m}$, de forma que não atende as necessidades de todos os usuários, principalmente, se ele for cadeirante. Quanto ao espaço de $0,60 \mathrm{~m}$ ao lado da maçaneta, que deve existir para a aproximação de pessoas em cadeiras de rodas, a residência se encontra acessível neste detalhe. E quanto a largura de seus vãos, as portas se encaixam na exigência de largura mínima de $0,80 \mathrm{~m}$. As fechaduras das janelas, por sua vez, não atendem ao solicitado, pois estão a $1,68 \mathrm{~m}$ do chão, enquanto a norma específica, no máximo, $1,20 \mathrm{~m}$.

Para áreas coletivas, em espaços de uso público, devem existir pelo menos uma rota que seja acessível, com pelo menos 1,20m de largura, contínua, desobstruída e sinalizada que interligue todos os ambientes da edificação e que deve estar vinculada às circulações principais e de emergência. No caso da UFERSA, para este critério, a residência está dentro dos padrões exigidos.

A edificação não apresenta desníveis no piso e, por este motivo, não há nenhuma rampa. Porém, há uma circulação vertical, vencida por meio de uma escada de dois lances e largura de $1,65 \mathrm{~m}$, dividida por um patamar de $1,20 \mathrm{~m}$ de comprimento, mas sem a presença de nenhuma plataforma elevatória. Os corrimãos da escada, atendem a altura de 0,90m, com presença de guarda corpo até o patamar, como ilustra a foto a seguir: 

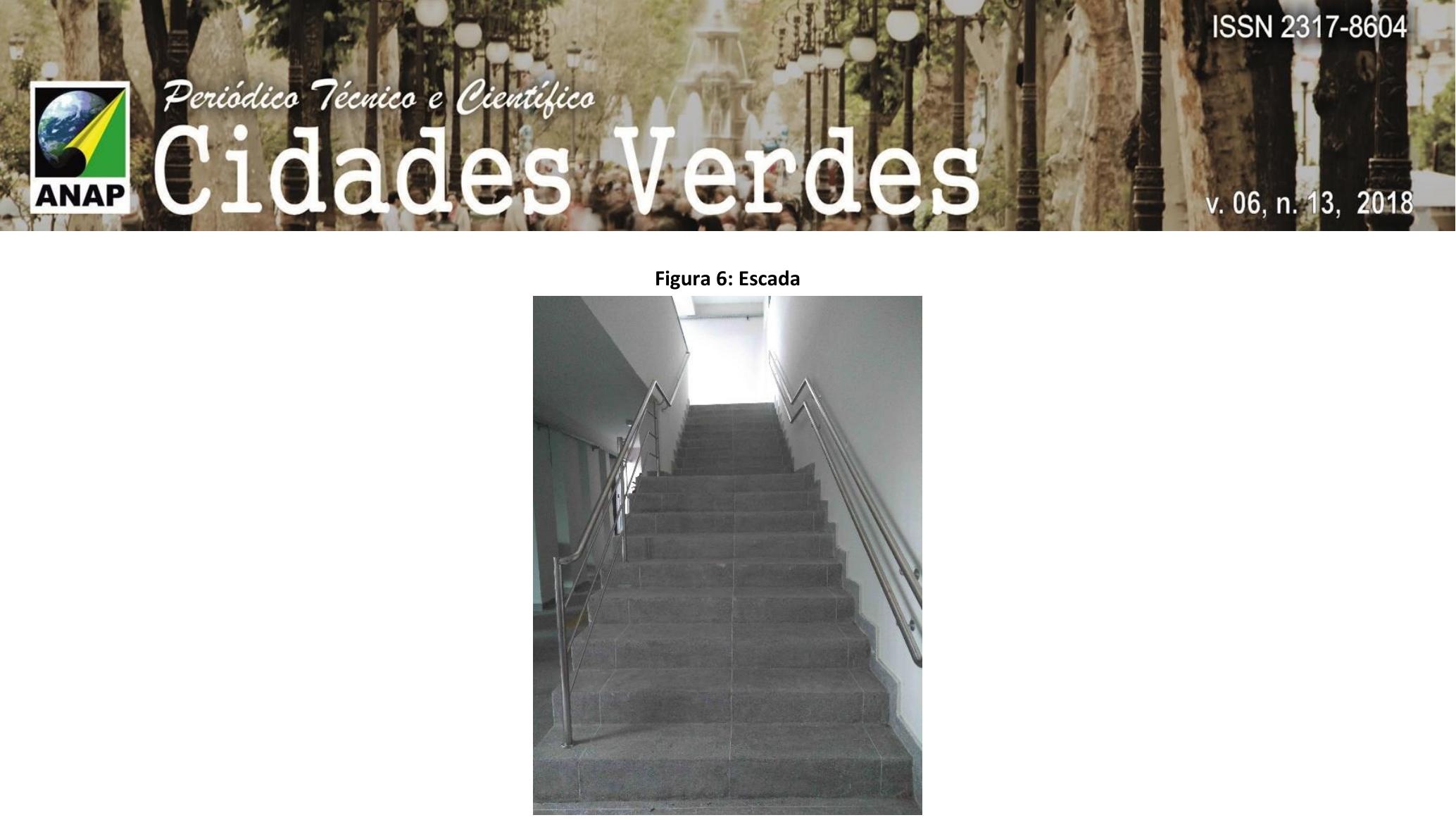

Fonte: CAPTURADA PELOS AUTORES.

Nos banheiros, a porta de entrada possui apenas $0,78 \mathrm{~m}$ de largura, não cumprindo, assim, a largura mínima exigida. Contudo, há entradas independes para os sanitários e chuveiros acessíveis, como sugere a norma, e sinalização de emergência, porém sem funcionamento. Existem apenas um sanitário e uma cabine para chuveiro acessíveis, ambos equipados com barras de apoio, conforme a norma. Entretanto, os lavatórios dos banheiros, não permitem a aproximação de uma pessoa em cadeira de rodas.

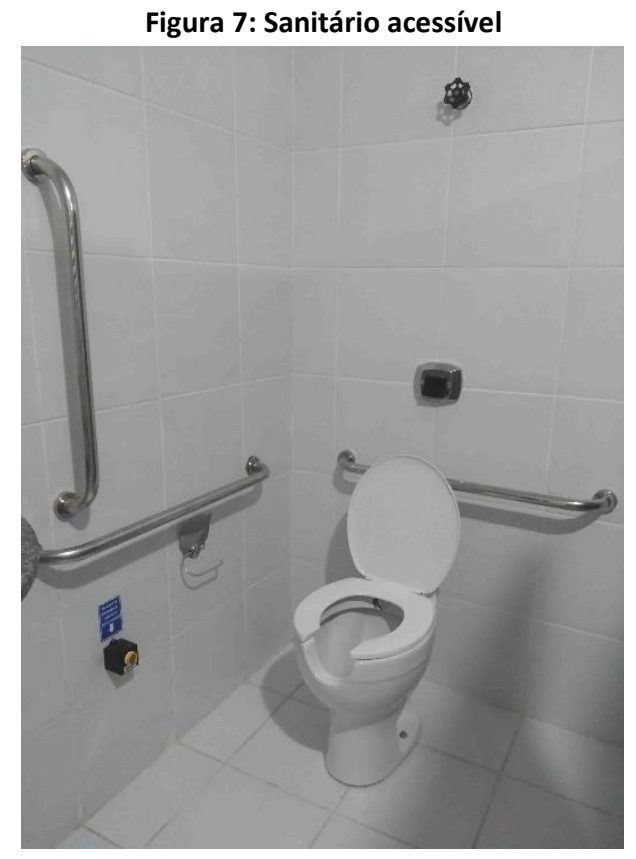

Fonte: CAPTURADA PELOS AUTORES. 


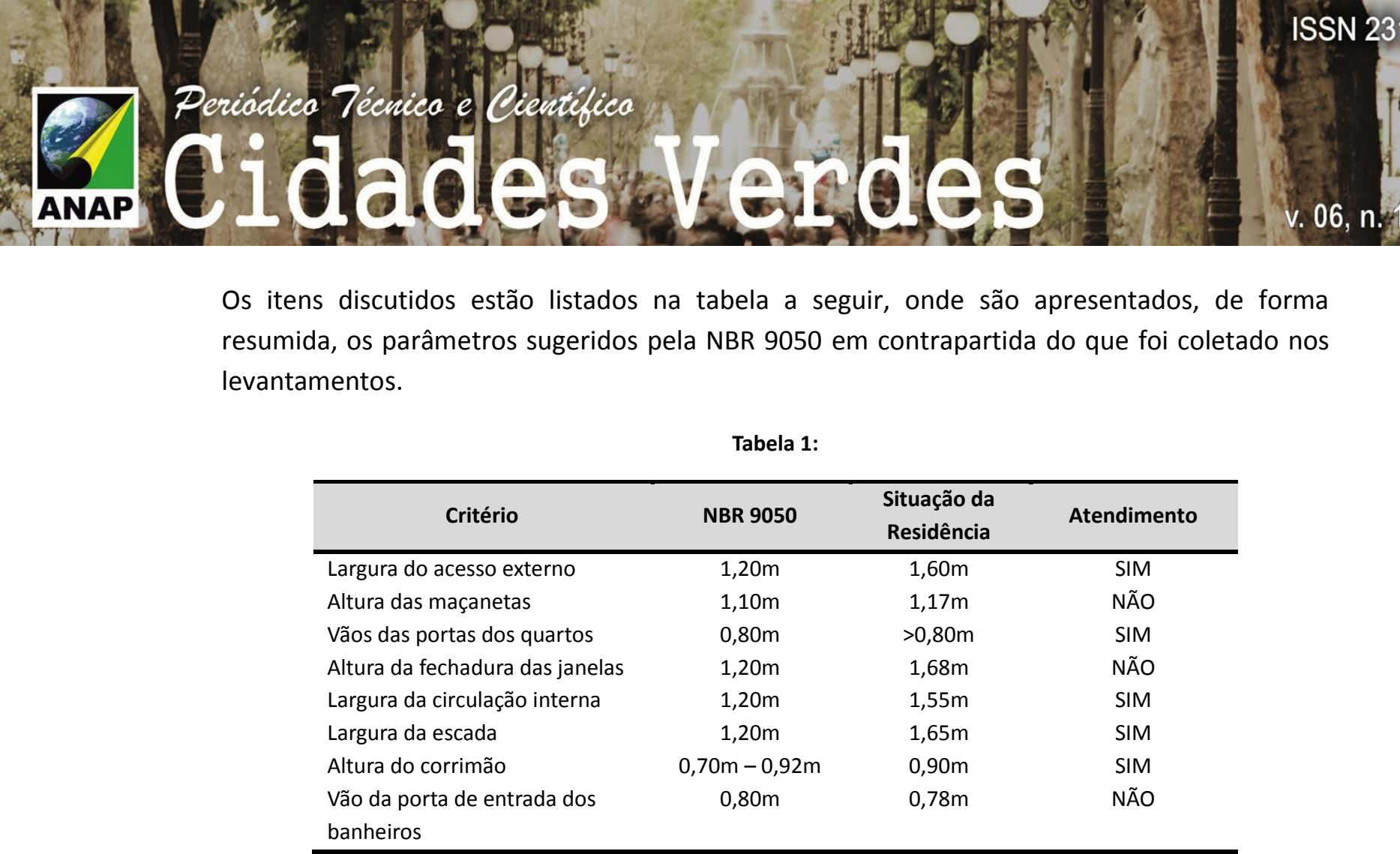

Fonte: Elaborado pelos autores.

\section{CONCLUSÃO}

Após a comparação feita entre as medidas coletadas na residência com as cotas indicadas nas plantas baixas e analisar a coerência da execução da obra com o disposto nas normas, foi o observado que, no processo de planejamento projetual, da residência, houve a preocupação de cumprimento dos parâmetros estabelecidos pela literatura dedicada ao assunto. $O$ grande embate está na execução deste projeto, onde ocorreram algumas modificações, fazendo com que o produto final não satisfaça por completo o plano de necessidades de uma residência que deve atender um público bastante diverso.

Diante disso, é importante que se faça uma breve reforma nos dois prédios da residência, apenas para corrigir o que foi negligenciado durante a construção, como a entrada dos banheiros que se encontra muito apertada para acesso de um cadeirante, por exemplo, a fim de atender mais rigorosamente o projeto, possibilitando, assim, uma inclusão ainda maior de todos que almejam ingressar no ensino superior sem nenhuma distinção.

\section{REFERÊNCIAS BIBLIOGRÁFICAS}

ABNT ASSOCIAÇÃO BRASILEIRA DE NORMAS TÉCNICAS. NBR 9050: Acessibilidade a edificações, mobiliário, espaços e equipamentos urbanos. Rio de Janeiro, 2015.

ALMEIDA, Ivonete M. da Silva. Acessibilidade Física nas Escola Públicas: Um problema de gestão?. 2012. Tese (Especialização em Gestão Pública Municipal) - Universidade Tecnológica Federal do Paraná, Curitiba.

BRASIL. Constituição (1988). Constituição da República Federativa do Brasil. DF: Senado, 1998.

BRASIL. Lei n. 9394, de 20 de dezembro de 1996. Estabelece as diretrizes e bases da educação nacional. Diário Oficial da União. Brasília, DF, 20 dez. 1996. Disponível em: <http://www.planalto.gov.br/Ccivil_03/leis/L9394.htm>. Acesso em: 02 abr. 2018. 


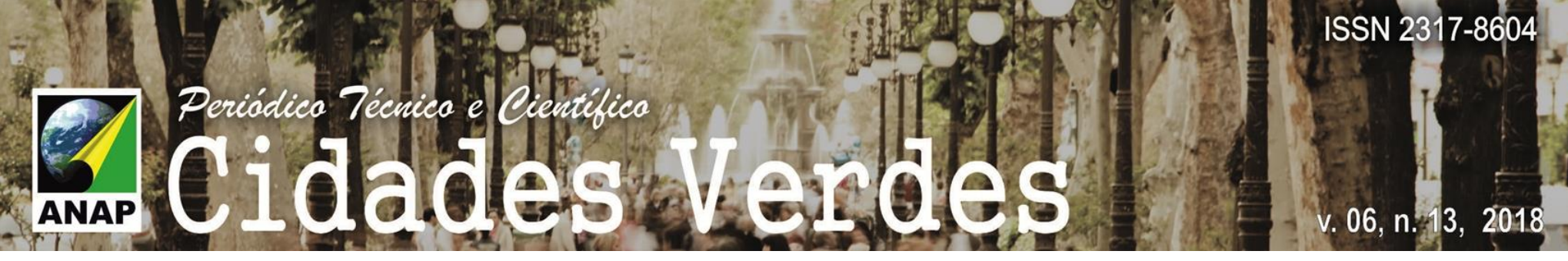

BRASIL. Ministério da Educação. Manual da Acessibilidade Espacial para Escolas: O direito à escola acessível!. Brasília, 2009. 120p. 